\title{
Changing professional identity in the transition from practitioner to lecturer in Higher Education: An Interpretive Phenomenological Analysis
}

\author{
Colin Wood, Dawn Goodall, and Mark D. Farmer
}

\begin{abstract}
:
This research explores the experiences of five professional practitioners from disciplines including teaching, youth work, sport and health who had become lecturers in Higher Education. Their experiences are considered using Interpretative Phenomenological Analysis and tentative conclusions are reached on the meaning of such experiences for the individuals. The work extends previous studies (Shreeve 2010, 2011; Gourlay 2011a, 2011b; Boyd \& Harris 2010) to consider the relationship between knowledge and influence and how institutional preference for knowledge gained from research impacts on the validity of knowledge derived from professional experience. The research finds shared feelings associated with inauthenticity and loss arising from concerns that the contribution of the professional in Higher Education is undervalued. The research challenges the assumption that professional practitioners adopt the professional identity of a lecturer in Higher Education instead finding that they create their own professional identities in the liminal space between the professional and academic domains, but points to difficulties associated with constructed nature of such professional identities within the institutional structure of a Higher Education institution.
\end{abstract}

Keywords: new lecturers; practitioners; transitions; academic identities;

\section{Introduction:}

Many Higher Education lecturers have had previous careers and professional experience in the field in which they become lecturers. The initial move to working in Higher Education is often based on the value placed by the Higher Education institution on their professional knowledge, experience and expertise as well as for their impact on the vocational currency of degrees and of research outputs. The transition from one career to another is characterized by changes in work practices, operational structures and work place cultures. Many of these operational changes are explicitly addressed in the move into Higher Education teaching through induction and mentoring. However the transition also requires adaptation to value systems that are rarely made explicit and that may conflict with those associated with the previous career. This may include value systems associated with status, authority, decision-making and accountability. Thus Higher Education lecturers who have had previous careers and professional experience may find the transition a period where their professional and personal values are contested and challenged, leaving the lecturer with little sense that they are contributing. Indeed this paper moves away from the narrative of a transition from one professional identity to another, and instead considers the experience of being 'in between' professional identities - in a liminal state - in which adaptation to new value systems requires lecturers to make compromises that are often made with incomplete information and within a social milieu that may appear to new lecturers as hierarchical and resistant to change.

In this study we use Interpretative Phenomenological Analysis (IPA) to consider the shared experiences of Higher Education lecturers who have had previous careers and professional experience in the fields in which they lecture. Participants were recruited from a single post-1992 university in England across a range of subject areas. Five participants, including one of the authors, were recruited by email and each fulfilled three criteria, namely that they were full-time university 
lecturers; were currently teaching in curriculum areas related to previous professional discipline, and had had a previous career of more than 10 years. Given the sensitive nature of the interviews, and in line with small scale studies, the participants' identities have been anonymised and creative non-fiction is used to obscure identity.

Our rationale for the use of Interpretive Phenomenological Analysis was that as biographically situated researchers we recognised that we shared aspects of our historicity with each other and with the participants. Indeed, the fact that we had chosen to examine the world of identity within Higher Education reflected the way that the researchers' own constructions of the world were intimately bound with the questions we asked. From the outset, we acknowledged that as socially situated researchers it was impossible to portray the experiences of others without our own construction of reality. Consequently we sought a methodology based on the interpretive practice of sense-making that aimed to reflect the "situated relational and textual structures" of the narrative accounts of both the participants and the researchers (Denzin and Lincoln 2013, 30). Indeed it seemed appropriate that when asking professionals to examine the changes in their professional identity that we offered a methodological position that was guided by phenomenological and hermeneutic enquiry (Smith and Eatough 2012) as we shared many of the experiences under investigation. As such we considered that IPA offered an account that embraced an attempt to both understand what it is to "stand in the shoes of the participant...while honestly accepting that this position can never be completely achieved" (441).

\section{Literature review:}

The experiences of professionals moving into Higher Education teaching have been considered previously across a range of fields and have received particular attention within health and education related disciplines. This review looks at the concept of professional identity with particular relation to the adaptation of professional identity during the transition to a new context or role. As such it draws on Ibarra's concept of the provisional self (Ibarra 1999, 2003) and on Van Maanen and Schein's (1979) concept of organisational socialisation These foundational texts are considered against the literature on the professional identity of Higher Education lecturers, and a smaller literature on transition to Higher Education teaching particularly work by Shreeve (2010, 2011) and Gourlay (2011a, 2011b), to develop a framework for the discussion of transitional experiences from other careers into Higher Education lecturing.

Schein (1978) defined professional identity as the relatively stable and enduring constellation of attributes, beliefs, values, motives and experiences in terms of which people define themselves in a professional role. This identifies a number of key components of identity, but also focuses the reader on identity as self-definition and as related to role. The core assumption of this constructivist approach is that professional identity becomes less malleable over time as people gain insight about their central and enduring preferences, talents and values. Ibarra (1999) moves away from the certainty of self-definition and proposes a more malleable form of professional identity that is more closely related to image. In his adaptation process model he looks at three areas that influence the adaptation outcomes, namely situational and personal variables; adaptation repertoire and the adaptation tasks. He suggests that people adapt to new professional roles by experimenting within a repertoire of identities and by selecting tasks to help them to transition, but that the possible outcomes are also influenced by the individual's past experiences, self-concept and motives, as well as the situational constraint. The concept of experimentation suggests that individuals go through a period of time where their professional identity is uncertain and unstable. Whilst Ibarra (1999) looked at junior staff many of the people moving into Higher Education have moved from senior 
posts with considerable status. Thus whilst Ibarra's concept of provisional selves (Ibarra 1999) recognises the agency of the individual and the interplay of individual and situational factors within the process of professional adaption to a new working environment, it does not recognise a role for pre-existing forms of professional identity or how individual reasons for change are maintained through the transition. These points are considered in later work, where Ibarra and Barbulescu (2010) consider both former professional identities and reasons for change within the concept of narrative. They suggest that narratives are critically important for our understanding of macro work role transitions. Here individuals construct narratives around large career changes to establish a sense of continuity, however such narratives are in part validation narratives and in part narratives of authenticity. They suggest that for a narrative to be successful it needs to be both credible and true to the sense of self, but that such narratives tend also to include plots such as heroic quests, coming-ofage stories, and rags-to riches plots that help to justify and explain the transition to self and others. However although provisional selves and the experimentation with constructed narratives recognises the centrality of the individual within the process of adaptation to a macro work-role transition it tends to present the situational factors as constants. This perhaps overlooks the active role taken by many employers in the form of support, advice and mentoring or indeed the management of expectations within the recruitment process. Thus the narratives that are developed to support a sense of continuity, validity and authenticity are influenced, or scaffolded, by the employers.

Shreeve $(2010,2011)$ looks at the sense of identity and personal narrative of practitioners working as part-time lecturers teaching in Higher Education. She finds that there are five distinct identities, and that each is based on a different narrative that links the two different cultural worlds of work and Higher Education. These include: dropping in - where the identity is positioned within the world of practice; moving across - where teaching is more to the fore than practice; two camps where there is symmetry between practice and teaching but where the identity is under threat in both worlds; balancing - again characterised by symmetry but where the relationships between both worlds are fluid; and integrating, where the identities are melded together into an artist-educator.

Shreeve (2010) extends the analysis developed in the earlier paper to suggest that some of these identities are uncomfortable and inefficient. She sees this as having consequences for the potential benefits

"Because there may be a tendency to rely on the employment of practitioners to teach a significant part of the curriculum, there should not be an assumption that this will entail either a comfortable or simple transition for the practitioner tutor or enable full access to current practice for students." (701)

Gourlay (2011a) also considers the liminal position between two worlds in a study of the experience of a new lecturer coming from professional practice into teaching in Higher Education. The study considers the direction and content of the support, particularly the over-reliance on PGCert programmes that focus on teaching and learning rather than acknowledging the 'emotional, ideological and subjective struggles' (591) and supporting the new lecturer through tacit knowledge and recognition of their contribution.

"Summing up, Sophie's story seems to bring into relief the depth of difference between higher education and some practice environments in terms of the values, emotions and ideologies which are explicitly or implicitly privileged - and, therefore, the losses that the new lecturer is expected to bear in order to make this transition. For Sophie this required her to relinquish values and subjectivities which formed a central part of her personal identity and professional practice. She chose to leave the academy rather than do that. In terms of 
directions for future research, this also invites speculations about what happens longer term to those who stay - whether they are forced to fragment in order to find a resolution, to 'leave the academy' in other ways - emotionally, intellectually, discursively - or whether they were ever allowed to wholly 'arrive' in the first place?" (600)

This interesting case study challenges the premise of Ibarra $(1999,2003)$ suggesting that moving into teaching in Higher Education is not a transition from being a practitioner to being a lecturer, but is a fundamental restructuring of personal and professional values in order to develop a personal resolution. The focus of Gourlay (2011a) is on the suffering involved in changing personal values and subjectivities, and through the fragmentation of a previous professional identity. There is no suggestion of the development of a personal narrative, suggested by Ibarra and Barbulescu (2010), that can justify the suffering nor is there evidence of personal agency, and thus it is clear from Gourlay (2011a) that the new lecturer has little autonomy and in consequence feels victimised by the expectations of the new establishment. This painful case study provides a challenging counterpoint to earlier texts that recognise the agency of the individual in the transition process, suggesting that such agency may be illusory for new lecturers who are required to accept the values, emotions and ideologies of the new environment regardless of their congruence with existing values.

Gourlay (2011b) also considers the unpleasant experiences of new lecturers from 'practice' and uses this to critique the idea of socialisation into a community of practice. Gourlay identifies three areas of shared experience: a sense of confusion, inauthenticity and isolation. She challenges whether the conditions for Lave and Wenger's (1991) concept of a community of practice are ever met. Instead she suggests that the repertoire of practice is not shared with new lecturers, that there is a perceived lack of mutual endeavour and that expert-novice interaction is rare. Whilst these are the same for all new lecturers she suggest that,

"this is arguably significantly greater for lecturers ... who have not only not undergone the $\mathrm{PhD}$ process, but have also constructed their sense of professional identities, practices and values in entirely contrasting 'practice' contexts centred on the enacted values of collaboration, sharing and care.”(76)

Gourlay (2011b) is not suggesting that these unpleasant experiences are merely the result of macro work role changes, rather that they are deeply felt as they relate to a disruption of personal values and self-image that have been developed over a long career.

"Their former professional identities as senior practitioners seem to be under threat, as they find themselves in the role of bewildered novices. Unlike the more structured environments of practice settings, the 'rules' for progress and success are reported as unclear and opaque. In terms of academic literacies and discourses, these new lecturers position themselves as outsiders and unsure amateurs, and seem to view this as a deficit." (75)

Boyd and Harris (2010) also identify significant tensions for new lecturers from practice. This article considers new lecturers in a 'not research intensive' university who have moved from being school teachers and again identifies feelings of feeling new and lacking credibility. Indeed their respondents viewed their role as 'teacher in Higher Education' rather than lecturer. The second aspect that Boyd and Harris report was the sense amongst new lecturers that their success as a school classroom teacher provided credibility amongst their students.

"Overall the new lecturers are seeking credibility through knowing and reconstructing their pedagogy, but they pursue this within a complex and confusing context that involves 
considerable amounts of boundary-crossing and uncertainty. They focus on teaching and on developing knowledge, with an eye on the students as their key audience, in relation to credibility as practitioners rather than as researchers. Within the case-study workplace context, the experiences of the new teacher educators encourage them to hold on to their existing identity as school teachers." (21)

Boyd and Harris (2010) are thus suggesting that new lecturers' credibility as practitioners is closely linked to students' opinion of their teaching particularly when using case studies, and that thus there is a strong incentive to retain their previous professional identity within the Higher Education environment. However by making the students the key audience, Boyd and Harris are implicitly suggesting that the retention of a previous identity leaves new lecturers uncertain about their credibility with colleagues, and insecure about their legitimacy to be presenting knowledge derived from areas other than professional practice. Thus the paper extends the discussion of previous papers about the discomfort experienced by new lecturers and the insecurity attached to making compromises between previous professional identities and those that they feel are expected within Higher Education.

In conclusion the recent authors including Shreeve (2010, 2011), Boyd and Harris (2010), and Gourlay (2011a, 2011b) have moved away from the mainstream literature on work transitions to develop a nuanced understanding of the experience of moving from practice into teaching in Higher Education. Their analysis suggests that this is not a staged progression from one state to another, but rather is a process of often painful compromises that involve the restructuring of values, self-image and pedagogy, and that these compromises result in individuals adopting one of five states that sit between the domains of practice and Higher Education.

\section{Methodology:}

In this investigative study we used recorded interviews with Higher Education lecturers to consider how their professional identity had changed during the transition from a previous career into teaching in Higher Education, and how they had managed the transitional period. Five participants were recruited by email and fulfilled three criteria, namely that they were full-time university lecturers; were currently teaching in curriculum areas related to previous professional discipline, and had had a previous career of more than 10 years. Participants were recruited from a single post1992 university in England across a range of subject areas. Given the sensitive nature of the interviews, and in line with small scale studies, the participants' identities have been anonymised and creative non-fiction is used to obscure identity.

An initial semi-structured interview was recorded with one of the researchers who fulfilled the criteria for inclusion as a participant; this was analyzed with relation to the experience of the phenomenon and in relation to theory. Themes and a core narrative were then developed for use in the conduct and analysis of 4 subsequent interviews. The initial interview not only acted as a pilot for later interviews, but through interpretive analysis and reflection with the participant provided an opportunity to combine empathic hermeneutics with a questioning or critical hermeneutics in line with Smith and Eatough's (2012) guidance for the effective use of Interpretive Phenomenological Analysis (IPA). The inclusion of participant researcher information is sometimes considered as problematic and in anticipation of such concerns the data from this initial interview was analysed independently of the subject, and the emergent themes and narrative derived were validated through comparison with subsequent interviews. Interviews were then conducted with the remaining participants and analysed in accordance with IPA methodology which allowed consideration of 
aspects of shared experience to develop emergent and superordinate themes.

Our rationale for the use of Interpretive Phenomenological Analysis was that as biographically situated researchers we recognised that we shared aspects of our historicity with each other and with the participants. Indeed, the fact that we had chosen to examine the world of identity within Higher Education reflected the way that the researchers' own constructions of the world were intimately bound with the questions we asked. From the outset, we acknowledged that as socially situated researchers it was impossible to portray the text free from constructions, rather we sought a methodology based on the interpretive practice of sense-making that aimed to reflect the "situated relational and textual structures of the narrative accounts of both the participants and the researchers" (Denzin and Lincoln 2013, 30). Indeed it seemed appropriate that when asking professionals to examine the changes in their professional identity that we offered a methodological position that was guided by phenomenological and hermeneutic enquiry (Smith and Eatough 2012) as the authors would in part share the experiences under investigation. As such we considered that IPA offered an account that embraced an attempt to understand what it is to "stand in the shoes of the participant " while honestly accepting that this position can never be completely achieved (441).

The methodology differs from classical forms of IPA in the inclusion of a researcher as a participant. This shared positionality when employing the double hermeneutic was advantageous as it provided access to those shifts in identity as facilitated by and mediated through a shared sense making approach. The semi-structured interviews were conducted employing both an empathetic and critical stance. This allowed the sense-making of the participant to remain central and acknowledged. The narrative was explored from the position of the individual as they recounted their experiences of identity change using inquisitive questions around these accounts. The aim was to uncover areas of shared and divergent sense making and uncover the relationship between cognition, account and behaviour. This allowed the researchers to position themselves as somewhat distant from the phenomena, in order to employ critical and interested questioning of the accounts, providing a richer and nuanced interrogation and a presentation of the lived experience.

IPA requires the researcher to retain a commitment to an ideographic level of analysis, employing an intensive examination of individual narratives in each of the cases. However, this ideographic starting point may also be framed as the "logical route to universal laws and structures" (Smith and Eatough 2012, 443). In line with many IPA studies, the question explored here is concerned with issues of significance to the participants, either around those things that are ongoing or located in a critical point in their life. IPA remains an effective way to explore issues that are transformative and are situated in accounts of self and identity (444). This research chose to maintain a small sample size and concentrate on offering nuanced accounts of a limited number of participants from a homogenous sample reflecting the interpretive stance of IPA. Interviews were used to create accounts that were recognisable to the individual but that were not anticipated by either the researcher or the participants and which offered enlightenment to the overall question (449).

The superordinate themes were revealed through an iterative process. Written analysis and discussion with authors and participants moved back and forth through interpretation of each participant's personal account with a determination to ensure that the integrity of the phenomena as experienced by the participant remained preserved as far as was possible (Smith and Eatough 2012, 455). After this was done for each case study it was possible to identify common themes within the narratives as well as themes which were divergent (Smith and Eatough 2012, 456). Thus what is presented is a close textual reading of the participant's account in the form of both description and interpretation (Smith and Eatough 2012, 455). To ensure that the IPA remained closely related to the texts of the interviews these were also subjected to thematic analysis and these findings are also 
presented.

\section{The participants:}

At the time of the study, all 5 participants were employed as full-time lecturers at a post-1992 university. All participants had had previous careers of over 10 years before teaching in Higher Education. Apart from Alice who had previously completed a doctorate, all other participants held a Masters degree and four participants held teaching awards.

Peter - a principle lecturer with over 20 years in Higher Education, previously held a senior position in a school and made the transition into Higher Education teaching whilst completing a Masters degree.

Sue - a senior lecturer with less than 5 years in Higher Education, previously a deputy head in a school.

Alice - Senior lecturer with over 10 years in Higher Education, previously a manager in a private health care organisation.

Tom - Principle lecturer with over 15 years in Higher Education, previously the regional director of a youth training organisation. and made the transition into Higher Education teaching whilst completing a Masters degree.

Interviews were also conducted with one of the authors:

Mark - a senior lecturer with over 10 years in Higher Education, previously a senior manager in youth and community work

The names of the participants have been changed and some elements of creative non-fiction have also been included to provide anonymity. All participants completed informed consent forms and were offered options to see all data and withdraw from the study at any time prior to submission for publication.

\section{Thematic analysis:}

All interviews were subjected to thematic analysis and IPA. Thematic analysis was based on La Pelle (2004). The interview with Mark was analysed independently by all three authors and this analysis was combined to generate codes and themes. This process also ensured some inter-rater reliability. Subsequent interviews were analysed by two authors and again the themes were combined to generate codes and themes.

With relation to the previous experiences of participants, all considered that they had had successful careers and identified themselves with a definable professional identity. All had experience of management or of positions of responsibility before coming to Higher Education. All had previous experience of teaching or training, 3 of the participants had supported Higher Education placements in the workplace, and 4 had previous experience of the development of the next generation of professionals in their field. Other themes that emerged were the length and variety of their careers, and a passion for their professional practice. An interesting feature was the participants' characterisation of management and responsibility as secondary to practice. All of the participants 
were able to identify a clear professional identity. However a range of different themes emerged when asked about the source of that identity. These included identity related to job titles; to involvement in a professional community of practice; to professional qualifications or to shared professional values. Interestingly, in 4 cases, participants identified a single source of identity, and in the remaining case one source was clearly dominant.

In consideration of the motivation behind the move to Higher Education (HE), there were two emergent themes: an intention to influence change in their own sector, and a personal ambition to be a lecturer. However there were 2 other themes that were discussed by three participants that suggest that their move was not intended as a change of career. Comments here related to a "natural progression into HE' or HE as a 'hobby'. In these instances it was unclear whether the participants were choosing to understate their own agency. Interestingly there was a clear division between participants with regard to the timescale of the change in identity, some identified a slow or gradual build up of identity and others a rapid change.

The main focus of the interviews was around the experiences of moving into Higher Education and these generated a wide range of responses that were coded as feelings and understandings of working in Higher Education. Most responses identified feelings of loss, a sense of insecurity, frustrations with values in Higher Education, and a lack of recognition for their experience and expertise in line with previous studies by Shreeve (2010, 201) and Gourlay (2011a, 2011b). Whilst these were balanced with some positive comments about opportunities for personal growth and for developing future professionals, the transitional experience was clearly a deeply uncomfortable experience for many participants over an extended period of time. Feelings centred on a sense of loss; characterised as a loss of professional currency, the loss of a previous role and the loss of opportunities to take responsibility.

All participants reported a sense of insecurity, sometimes characterised as a sense of fraudulence or of being in the wrong place. Other themes included not being understood by others, sense of uncertainty and self-questioning and unfulfilled expectations of increased status. In addition three participants reported a sense that research-based colleagues lacked professional credibility. Allied to these feelings were strong statements about the nature of working in Higher Education. Here all participants noted a lack of institutional recognition for vocational experience and expertise and a high valuation given to academic qualifications. Other emergent themes included a perception of the slow pace of change in Higher Education and limited opportunities for promotion and career enhancement particularly for those with professional backgrounds.

When asked about their current or emerging professional identity within Higher Education two clear themes emerged showing very different descriptions of identity. The first was as an 'educator preparing students for professional practice' and the second as a 'practitioner working within HE'. These two categories were mutually exclusive suggesting that these were discrete identities rather than different perspectives on a single identity. This finding supports the model developed by Shreeve (2011) that identified five discrete states lying between the previous professional identity and the identity of a Higher Education lecturer. It also supports the observations of Boyd and Harris (2010) that new lecturers from a professional background tend to focus on the aspects of their job where they feel they have most credibility with their students.

Within the uncomfortable period of transition, participants identified two main strategies for supporting their emerging identity: focussing on the quality of teaching, and maintaining professional currency outside of teaching. These strategies were not mutually exclusive and in some cases were supported by motivational strategies that included focusing on areas where they were 
able to contribute, drawing parallels between good practice in their previous profession and in Higher Education; seeing Higher Education as a challenge and another step on; and ensuring their own emotional safety through compartmentalisation.

In conclusion, the thematic analysis generated a clear picture of ambitious, capable individuals with backgrounds that included high levels of responsibility and previous experience of teaching or training. Their motivations were somewhat less clear with the strongest responses around wanting to make a difference. There was near unanimity on the emotional experience of moving into Higher Education and a shared analysis about the low institutional value placed on vocational experience. However all participants had implemented strategies to support their move, and all participants were able to describe an identity that included elements of both professional domains.

\section{Interpretative Phenomenological Analysis:}

\section{Embracing the liminal state}

This section explores some of the issues raised by Shreeve $(2010,2011)$ and Gourlay (2011a, 2011b) through the experiences of the participants and the interpretation of the authors. Within this we look at whether the change of identities is a result of organisational socialisation (Van Maanen and Schein 1979) or involvement in communities of practice (Lave and Wenger 1991), is a process of self-definition (Schein 1978), or is a liminal state in which individuals experiment with identities (Ibarra 1999) and with narratives to support those identities (Ibarra and Barbulescu 2010).

Our initial analysis was based on the idea that the experience of becoming an academic member of staff within Higher Education was transitional, leading from a stable professional identity in a previous career to a stable professional identity within Higher Education teaching. Such a transition implies both motivation to change and a process of change, and the interview plan sought to identify these. However the responses did not support this as none of the interviewees identified themselves with a single professional identity within Higher Education teaching with participants using terms such as Applied Lecturer, Practitioner in HE, Coach-educator. Indeed there was no evidence of further stages of identity change between "Sue" with only a few years of experience and Peter with over 20 years. Thus our research suggests that identity far from transitioning actually establishes itself within the middle ground and embraces and accommodates a range of states. This accords with Shreeve's (2011) concept of 5 states, and indeed her findings about some identities being uncomfortable and inefficient are also reflected in the responses. Thus Mark describes his transition as:

"in terms of identity... I have been able to achieve all that I have achieved to this point with the identity that I brought with me ... I've launched a number of courses, I've managed quite a challenging programme in terms of work based learning and professional requirements. I've worked with colleagues in an environment where you have absolutely no power, but you have all the responsibilities so everything has to be negotiated, but I've done that using everything that I brought with me, I haven't needed to learn new things except the context." Mark 71

Clearly this is a stable state with little evidence of transition, or ongoing change. It appears effective within its own terms of reference. However two things are clear, that there is little engagement with knowledge creation, and that there is no evidence that the position was arrived at by organisational 
socialisation or by involvement in a community of practice. The passage only has a single mention of others and the identity is clearly linked to individual endeavour.

By contrast Peter has a different response and arrives at a different state:

"You know I use the word academic, but I wasn't academic I was more applied, so obviously when I went to [name of previous university] there were really clear directives about being involved in research so whilst I was learning to, I was getting familiar with the demands of research. I had to do more reading, but that fitted in quite well with the types of support that the students needed." Peter 14

Here Peter distinguishes himself as an applied lecturer as distinct from an academic lecturer, although he shows how the University's expectations clearly include research. His feelings in this period include a discomfort with his academic role and the transition to a research focus, but again his state is largely unchanged with all later discussion of outcomes and roles related to developing students. Peter appears to have arrived at an integrated professional identity as an educator preparing students for professional practice and thus redefining the relationship with professional practice through the future of his students. This is in stark contrast to the uncomfortable state of Alice,

"Yeah - I think it has definitely changed, definitely, because when I was working as an [medical professional] I was trained [professional] staff, working in HE you don't have that same persona you don't have that identity any more, you are not a trained [professional] staff person any more. You are just another lecturer, and to be honest a lot of people don't really know what you are, what your training is, it seems invisible..." Alice 28

Alice seems to have a sense of a move from being clearly labelled to wrongly labelled, and the concept of labelling is returned to later as it clearly seems to be a source of tension with a clear rejection of the identity / label of 'just another lecturer'. Even after 10 years in Higher Education teaching this concern over labels seems to reflect strong association with her professional practice and thus she identifies herself as an outsider in a new culture. Again, despite Alice's claim to have changed, there is little evidence of any ongoing change. Certainly Ibarra (1999) concept of provisional selves does not seem appropriate. Once again the passage shows no evidence of socialisation, communities of practice or experimentation with provisional identities, and little evidence of any ongoing process of identity change.

Similarly Sue as a newly arrived lecturer has also found it an uncomfortable experience,

"I think I am such a perfectionist that I want to come into this role and just know exactly what I am doing, and do it and do it well. ... and now I am coming in and actually I guess feel slightly maybe regressed in terms of where I am at... I guess I've gone down a few rungs." Sue 34

In this instance the description of identity is based on the opinions of her peer group in professional practice.

"I have to remind myself that actually when I talk to friends in teaching they are like "wow you're lecturing in a university", and it makes me remember actually yeah I should feel good about it, and people do... I think internally it's how I view it and where my career has gone I feel that actually my peers in teaching respect it, so yeah I think my identity is building up again to a level where it was before, it's just not quite there at the moment." Sue 34 
This is a fascinating passage that indicates considerable external validation for the move into Higher Education and how this impacts positively on the sense of identity, but that it is hard to unite this with a sense of being unable to be fully effective or contribute effectively, and a lack of status within the organisation. Again this reflects tensions and frustrations for the individual in moving from the top of a successful career into Higher Education and points to a split between the perception of working in Higher Education and the reality as experienced by the individual. Interestingly though there is a strong link here with effectiveness and when Sue later describes lecturing to trainee teachers it is clear that this is very close to the ideal that brought her into Higher Education teaching. Thus within a very short period of time Sue appears to have established her identity as a teachereducator, and in that is similar to Peter.

Within all of the above quotations it is clear that the move into Higher Education teaching has been problematic. Gourlay (2011b) describes this as a sense of confusion, inauthenticity and isolation and suggests that it is common to all new lecturers but 'arguably significantly greater' for lecturers from practice. This sense of confusion, inauthenticity and isolation is reported by all participants. However alongside this it is clear that there is also an awareness of the risks associated with becoming a lecturer. The transition to a new and poorly defined identity risks losing that which is most important: their experience, their passion and commitment to a particular form or field of endeavour. Thus entering Higher Education as an academic member of staff requires individuals to accept a state that is poorly defined and in doing so risks loss of identity and career. Boyd and Harris (2010) suggest that this often results in a focus on teaching and developing knowledge with an eye on their students rather than as researchers, and again this is apparent in the responses.

Thus our research suggests that identity embraces and accommodates a range of states that reflect a dynamic tension between the professional domain and the academic domain. None of our interviewees felt that they had made a full transition, and none appeared to be seeking to change. Indeed all had motivations and ambitions that related to their previous domain - to influence the future of their field through the development of the next generation of practitioners.

Exercising Influence through Knowledge in the liminal state

It is easy to see the space between the professional domain and the academic domain as a form of limbo, but all of the participants have chosen to remain in this space and most have arrived at compromises that allow them to establish an identity, or state, that draws on both domains. Not only are these states related to identity they are also closely related to influence. This is significant as all of the participants described their motivation to teach in Higher Education as related to making a difference:

"I thought the opportunity to create a new course was the opportunity to really count..." Mark 43

"My motivation was to try and produce teachers for tomorrow," Peter 20

"I am looking to improve an area of PE and hopefully somebody might read it and maybe..." Sue 48

"Yeah yeah, I mean I suppose now I've started to think of myself more as a coach educator. Educating coaches of the future." Tom 26 
"It's one of my best assets in teaching because not only do I understand the theory but I can understand how you use it." Alice 56

Here each respondent recognises that the raw material of Higher Education is knowledge and that their desire to affect change within their profession relates to their ability to influence the knowledge-base of that field. However there are different ways to influence knowledge and our research tentatively suggests that satisfaction, tension and/or frustration emerge when action is achieved or denied within one of four domains of influence.

- Administration and Management - The organisation of knowledge - Influence over the access to what is known

○ Teaching - The conveyance of knowledge - Influence over the teaching of what is known

- Curriculum Design - The promotion of knowledge - Influence over the value placed on what is known

○ Research - The formulation (creation) of knowledge - Influence over the generation of what is known

When Mark considers new course development he is seeing this as an opportunity to influence his previous field. When Alice engages in discussion with colleagues over the content of courses she too is seeking to influence the preparedness of the next generation of professionals. When Peter looks to develop the teachers of the future, he is again seeking to influence knowledge in the field.

However influence remains a major source of tension for the participants.

"I do feel (that) I've got an awful lot of knowledge and experience and I do feel that that is not valued now. That might change later on, I hope it does, but it is almost like 15 years of passion and umm learning about the profession and putting my heart and soul into it doesn't count for an awful lot when you make the transition. It's more about what have you written and have you been published, and as a teacher you don't have time to do that." Sue 28

Here Sue sees that she does not have influence through publication, and thus that her influence is limited to teaching. There is a palpable sense of disappointment and almost betrayal here that shows a depth of feeling as well as a determination to struggle through this.

Mark shows an alternative approach. He seeks influence through curriculum design and course management and is effective in doing so.

"I got involved in training whilst I was in management because again I could influence, and it's a sort of recognition that if I do face to face work I have influence over those people I have direct contact with... I moved here because I thought the opportunity to create a new course was the opportunity to really count... so the contribution then became one of curriculum development in terms of the course and course administration and general operations of the university, and it was far less about my identity really.” Mark 43

Thus influence within the professional domain appears to be a key motivator for professionals to move into Higher Education, and access to influence provides a justification for the compromises and sense of dislocation experienced by the participants. However we suggest that there are different ways to exercise influence and that individual circumstances as much as personal preference may 
determine the means by which a professional seeks to exercise their influence.

\section{Addressing the Hierarchy of Influence through Knowledge}

The forms of influence can be represented within a hierarchy because of the ways that academic institutions endow power and status. The participants are intently aware that some forms of influence are more highly valued than others, broadly these are:

\section{Formulating knowledge \\ 2. Promoting knowledge \\ 3. Conveying knowledge \\ 4. Administering knowledge}

As a key motivation for making the transition into teaching in Higher Education relates to wanting to influence or 'make a difference' to the previous field, all the participants have had to develop a strategy that recognises the hierarchical nature of their institution, and yet still allows them to exert influence. As Mark puts it,

"Actually to survive and thrive within an institution like this you have to look at what is valued and has status within the institution... and it isn't someone that is very very good at running courses." Mark 49

Thus the formulation of knowledge is preferenced, whilst administering knowledge and the conveying of knowledge is viewed as less important. However the exercise of influence within a social group provides a source of tension where others also wish to influence change in the same field but have a different agenda. This is particularly evident where they do not come from a professional background or where the influence is mediated by different levels of status.

"I find that interesting when I have to fight with colleagues about what it is like in the real world. Especially when they haven't actually ever done the job, I find that quite difficult." Alice 82

Here Alice has a depth of professional practice and yet is frustrated that the knowledge that she brings is not valued highly. She seeks to influence curriculum and her identification with the professional future of students provides a strong justification for challenging her colleagues about the vocational content and relevance of courses. Similarly Tom considers the lack of credibility of lecturers without professional practice. He suggests that they may lack the ability to think outside of the box or to bring new insights to the field, and yet acknowledges that they have greater influence because of the preference given to formulating knowledge and promoting knowledge. Again there is recognition that knowledge is the raw material of Higher Education but that the prioritisation of knowledge derived from knowledge creation means that there is institutional bias against knowledge that originates in practice.

"I think if you are a researcher and you want to go up the ladder from masters to doctorate to professor I don't think you would get that if you were an applied practitioner.” Tom 36

Here Tom notes that promotion (and thus influence and status) in Higher Education is strongly biased against applied practitioners. There is no clear sense that this is seen as a demotivating factor for applied lecturers, merely an observation. Indeed he continues: 
"I think if we were looking to... if higher education is looking to have an influence over more people from industry, they've got to contribute and balance up the teams, yes academic teams. I think we can do it better." Tom 40

This is a key passage that provides a clear rationale for practitioners' transition to Higher Education, namely to contribute to the field and to have influence over the industry. This is a really important insight as it provides a clear rationale for involvement, but also a basis on which to judge performance and success within Higher Education. It is also a criticism of the poor link between professional practice and teaching, and yet it recognises the value of both academic and professional routes. Thus Tom sees the solution as a move away from the concept of a hierarchy of influence and towards a teamwork model that provides parity of influence.

"I think we sometimes need to remind (academic) teams of... you know, a team is a team: a goal scorer, a fast player, a blocker and, guess what, without them we don't win anything. So it's knowing where you fit, why you were recruited in the first place and (being) reminded that you are still contributing." Tom 44

This moves away from the individual concept of identity to see it as situated within a team context where the strength of the team is not improved by homogeneity, but by members fulfilling different roles. This is neither occupational socialisation nor the development of a community of practice as it recognises the value of diversity and personal agency. Here the applied practitioner contributes vocational relevance and craft knowledge that sits alongside research skills and other areas of speciality to develop a strong and successful team. As a justification for applied practitioners this allows differentness and exceptionality to be valued as key features of lecturers from a professional background, and show that these have equal value to those from more academic routes.

However other participants struggled with the concept that professional experience might have equal value in an unequal environment. Participants referred repeatedly to credentials particularly the $\mathrm{PhD}$ which tend to favour knowledge formation through research and publication, and job titles which define hierarchy (eg lecturer, senior lecturer) rather than specialty or experience.

"I need to prove that I can do this, yes, I need to prove that I can write and I can be published and I want to have what I am viewing that this career is about, and that was in a survey that students value experience more than research profile, but ... I want both." Sue 40

It is perhaps rather poignant that even those with a depth of experience, expertise and knowledge feel drawn to the status associated with research and publication rather than the aspects of their role where they can exercise most influence - in the teaching of the next generation and the development of curriculum. Perhaps for those existing within a liminal state there is a strong attraction to being an insider and having status, but this seems to negate the value of attracting professionals into Higher Education. To extend Tom's analogy, if you are recruited as a goal keeper then you should aspire to be a good goal keeper, rather than try to score goals.

\section{Conclusions}

Through Interpretative Phenomenological Analysis, this research has explored the experiences of professional practitioners who had moved into Higher Education within a single Higher Education institution. We have interpreted the experiences and drawn some tentative conclusions about the 
meaning of such experiences for the individuals. In large part this has supported the findings of previous studies, but our analysis has led us to consider the relationship between knowledge and influence and how institutional preferences for knowledge gained from research tend to devalue the established knowledge derived from professional experience. In consequence, our study suggests that professionals moving into Higher Education may find their strongest asset undervalued within the operation of Higher Education institutions and that this may lead to the sense of insecurity and inauthenticity identified in this study and in previous studies.

The findings of the study also challenge the characterisation of these experiences as a transition from one professional identity to another, finding that all of the individuals located themselves in the space between identities whilst maintaining a commitment to inform and influence their previous field of endeavour. Thus it was unclear that any of the participants aspired to transition to the identity of a Higher Education lecturer. However the paper shares concerns raised by previous authors that the liminal space between professional and academic domains is poorly understood and that professional identities here are largely self-constructed and consequently are often insecure and may not be highly valued by others within Higher Education. Our findings also confirms previous studies that validation within this liminal space may be derived through endorsement from professional colleagues outside of the university system, in the form of recognition of the status and value placed on Higher Education lecturing from within the field of practice. Thus it seems likely that people who have been successful and well-established in their previous professional domain may find themselves adrift in Higher Education, until they arrive at a way of exercising influence on their previous field. Where they achieve such influence, whether in teaching, curriculum design, course leadership or research, their new professional identity is validated, resolving for a time the need to transition further towards a separate professional identity as lecturer in Higher Education.

Whilst recognising that this study drew on a small sample and was conducted in a single institution the findings show strong similarities to previous studies with different cohorts and in different institutions. Thus it seems possible that the experiences of participants in this study may be similar to those in other Higher Education institutions. If this is true then it would seem important to seek ways to develop recruitment and management processes to recognise the value of professional experience, and to better support Higher Education lecturers who have had previous careers and professional experience to develop professional identities that enable them to fully contribute to Higher Education. 


\section{References}

Boyd, Pete and Kim Harris. 2010. "Becoming a university lecturer in teacher education: expert school teachers reconstructing their pedagogy and identity" Professional Development in Education 36 (1-2): 9-24.

Denzin, Norman and Yvonna Lincoln. 2013. The Landscape of Qualitative Research (fourth edition). London: Sage publications.

Gourlay, Lesley. 2011. “I'd landed on the moon': a new lecturer leaves the academy” Teaching in Higher Education 16(5): 591-601.

Gourlay, Lesley. 2011. "New lecturers and the myth of "communities of practice"" Studies in Continuing Education 33(1): 67-77.

Ibarra, Herminia. 1999. "Provisional selves: Experimenting with image and identity in professional adaptation” Administrative Science Quarterly 44 (4): 764-791.

Ibarra, Herminia. 2003. Working identity: Unconventional strategies for reinventing your career. Harvard Business Press.

Ibarra, Herminia., and Deshpande Prashant. 2007. "Networks and identities: Reciprocal influences on career processes and outcomes". Handbook of career studies, 268-282.

Ibarra, Herminia., \& Roxana Barbulescu. 2010. "Identity as narrative: Prevalence, effectiveness, and consequences of narrative identity work in macro work role transitions" Academy of Management Review 35(1), 135-154.

Jones, Rebecca. 2012. "Reflecting on the Transition from Practice to Education - The Journey to Becoming an Effective Teacher in Higher Education” Journal of pedagogic development 2 (2): $11-15$.

La Pelle, Nancy. 2004. "Simplifying qualitative data analysis using general purpose software tools" Field Methods 16 (1): 85-108.

Lave, Jean., and Etienne Wenger. 1991. Situated learning: Legitimate peripheral participation. Cambridge: Cambridge University Press.

Schein, Edgar. 1978. Career Dynamics: Matching Individual and Organizational Needs. Reading MA: Addison-Wesley.

Shreeve, Alison. 2010. "A phenomenographic study of the relationship between professional practice and teaching your practice to others" Studies in Higher Education 35(6): 691-703.

Shreeve, Alison.2011. "Being in two camps: Conflicting experiences for practice-based academics" Studies in Continuing Education 33(1): 79-91.

Smith, Jonathon., and Virginia Eatough. 2012. "Interpretative phenomenological analysis" In Research Methods in Psychology 4th Edition, edited by G.M. Breakwell, J.A. Smith \& D.B. Wright. London: Sage: 439-461. 
Van Maanen, John. 2010. "Identity work and control in occupational communities." Chapter 5 in Organisational Control, edited by Sim Sitkin, Laura Cardinal and Katinka Bijlsma-Frankema. Cambridge: Cambridge University Press.

Van Maanen, John., and Edgar Schein. 1979."Toward of Theory of Organizational Socialization." Research in Organizational Behavior 1: 209-264. 